\title{
Characterization of natural low transition temperature mixtures (LTTMs): Green solvents for biomass delignification
}

\author{
Chung Loong Yiin a , Armando T. Quitain ${ }^{\mathrm{b}}$, Suzana Yusup ${ }^{\mathrm{a}, *}$, Mitsuru Sasaki ${ }^{\mathrm{b}}$, Yoshimitsu Uemura ${ }^{\mathrm{a}}$, \\ Tetsuya Kida ${ }^{\mathrm{b}}$ \\ a Biomass Processing Technology Cluster, Center of Biofuel and Biochemical Research, Mission Oriented Research (Green Technology), Chemical Engineering Department, \\ Universiti Teknologi PETRONAS, Bandar Seri Iskandar, 32610 Tronoh, Perak, Malaysia \\ ${ }^{\mathrm{b}}$ Department of Applied Chemistry and Biochemistry, Kumamoto University, 2-39-1 Kurokami, Chuo-ku, Kumamoto 860-8555, Japan
}

\section{H I G H L I G H T S}

- Cheap and commercially available starting materials.

- Enhancement of lignin solubility capacity with the presence of water.

- Pretreatment of real biomass was consistent with biopolymers solubility of LTTMs.

- Physicochemical properties of LTTMs were not affected by the presence of water.

- Green alternative in utilizing the microwave hydrothermal extracted malic acid.

\section{A R T I C L E I N F O}

\section{Article history:}

Received 22 June 2015

Received in revised form 26 July 2015

Accepted 27 July 2015

Available online 1 August 2015

\section{Keywords:}

Low transition temperature mixture (LTTM)

Water

Physicochemical property

Biopolymer solubility

Pretreatment
G R A P H I C A L A B S T R A C T

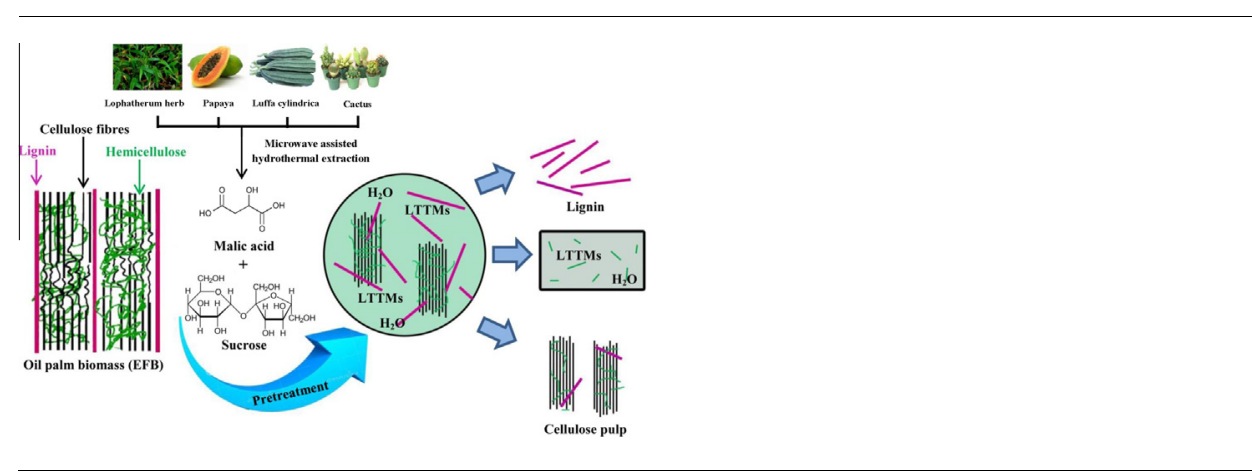

\begin{abstract}
A B S T R A C T
The aim of this work was to characterize the natural low transition temperature mixtures (LTTMs) as promising green solvents for biomass pretreatment with the critical characteristics of cheap, biodegradable and renewable, which overcome the limitations of ionic liquids (ILs). The LTTMs were derived from inexpensive commercially available hydrogen bond acceptor (HBA) and L-malic acid as the hydrogen bond donor (HBD) in distinct molar ratios of starting materials and water. The peaks involved in the $\mathrm{H}$-bonding shifted and became broader for the $\mathrm{OH}$ groups. The thermal properties of the LTTMs were not affected by water while the biopolymers solubility capacity of LTTMs was improved with the increased molar ratio of water and treatment temperature. The pretreatment of oil palm biomass was consistence with the screening on solubility of biopolymers. This work provides a cost-effective alternative to utilize microwave hydrothermal extracted green solvents such as malic acid from natural fruits and plants.
\end{abstract}

(c) 2015 Elsevier Ltd. All rights reserved.

\section{Introduction}

The global depletion of fossil fuels such as crude oil and natural gas will leave us with just renewable energy sources to rely on.

\footnotetext{
* Corresponding author. Tel.: +60 53687642; fax: +60 53688204.

E-mail addresses: ychungloong2009@gmail.com (C.L. Yiin), quitain@ kumamoto-u.ac.jp (A.T. Quitain), drsuzana_yusuf@petronas.com.my (S. Yusup), msasaki@kumamoto-u.ac.jp (M. Sasaki), yoshimitsu_uemura@petronas.com.my (Y. Uemura), tetsuya@kumamoto-u.ac.jp (T. Kida).
}

Nilsen et al. (2007) highlighted that unlike other renewable sources of energy such as solar and wind, which merely generates heat and power, biomass can be converted into liquid, solid and gaseous fuels. A lignocellulosic biomass contains 35-50\% cellulose, $35 \%$ hemicelluloses, 5-30\% lignin and a few percentages of extractives. Cellulose is the most abundant biopolymer on earth, thus it is a valuable source of raw materials for chemical and fuel industries (Maki-Arvela et al., 2010). An effective separation of these components and their subsequent fractionation are required for the 